Pacific Journal of Mathematics

A SINGULAR NONLINEAR BOUNDARY VALUE PROBLEM 


\title{
A SINGULAR NONLINEAR BOUNDARY VALUE PROBLEM
}

\author{
JACK W. MACKI
}

\begin{abstract}
We consider the singular nonlinear boundary value problem (BVP)

$$
\begin{gathered}
\ddot{y}-y+y F\left(y^{2}, t\right)=0, \quad t \in(0, \infty) \\
y(0)=0, \lim _{t \rightarrow \infty} y(t)=0, \dot{y}(0) \text { exists, } y(t)>0 \text { on }(0, \infty) .
\end{gathered}
$$

The problem is singular in a second way, in that we will allow $F(\eta, t)$ to have a singularity at $t=0$.

The problem is motivated by a nuclear model due to Takahashi [6], his equation (after some simplifications by Synge [5]) was $\ddot{x}+(2 / t) \dot{x}=x-x|x|^{k-1}$ with $k=2$; Nehari [2] wrote $x(t)=t^{-1} y(t)$ to transform this equation into

$$
\ddot{y}-y+y \frac{|y|^{k-1}}{t^{k-1}}=0 .
$$

Nehari showed that the BVP (3) (2) has a (not necessarily unique) solution for $1<k \leqq 4$. If one drops the requirement that $\dot{y}(0)$ exist, then there is a solution for $1<k<5$. Sansone used techniques entirely different from those of Nehari in an exhaustive study [4] in which he showed that (3) (2) has a unique solution for $1<k<5$; he used an extension of a counterexample of Nehari to show that there is no solution of (3) (2) for $k \geqq 5$.

Ryder [3] extended the variational techniques of Nehari, as developed in [1], [2], to the more general problem (1) (2). However, his results when applied to the special case of (3) (2) only yield existence for $1<k<4$; if one drops the requirement that $\dot{u}(0)$ exist, then his techniques prove existence for $1<k<5$.

In this paper we improve the results of Ryder, with the result that when we specialize to the BVP (3) (2) we prove existence for the full range $1<k<5$, thus improving Nehari's results as well. Throughout the remainder of this paper we will assume:

(I ) $F(\eta, t) \in C([0, \infty) \times(0, \infty)), F(\eta, t)>0$ for $\eta>0$.

(II) $\exists \delta>0$ such that for each $t>0, \eta^{-\delta} F(\eta, t)$ is strictly increasing in $\eta$ on $[0, \infty)$. In particular, $\lim _{\eta \rightarrow 0} \eta^{-\delta} F(\eta, t)$ exists for $t>0$.

(III) $\lim _{t \rightarrow \infty} F\left(c^{2}, t\right)=0$ for any constant $c$.

(IV) For some fixed $\varepsilon>0$ (hence for all smaller values of $\varepsilon$ ) $\int_{0}^{1} t^{1-\varepsilon} F\left(c^{2} t, t\right) d t$ converges for any constant $c$. 
The first three assumptions coincide with those of Ryder. In place of IV, he assumes $\int_{0}^{1} t^{(1 / 2)-8} F\left(c^{2} t, t\right) d t$ converges for all sufficiently small $\varepsilon>0$ (he uses IV to prove weaker results). Our version of IV allows $F$ to be more strongly singular at $t=0$.

Our approach is the same as that of Ryder, which in turn is based on that of Nehari, although we present our facts in a different order. However, since Ryder in turn refers to two different papers of Nehari for certain details, we feel it is necessary for the reader's sake to present a complete development. Also, our improvements come into Ryder's proofs in such a way that it is easier to do the entire proof. In order to help the continuity of the presentation, we have relegated all proofs to an appendix. The crucial new idea is Lemma 4.

We define $G\left(y^{2}, t\right)=\int_{0}^{y^{2}} F(\eta, t) d \eta$, and consider the variational problem

$$
\begin{gathered}
\min _{A} J(y) \equiv \min _{A} \int_{0}^{\infty}\left[\dot{y}^{2}+y^{2}-G\left(y^{2}, \tau\right)\right] d \tau \\
A=\left\{y \mid y(0)=0, y(t) \not \equiv 0, y \in D^{\prime}[0, \infty), y(t) \geqq 0, \int_{0}^{\infty}\left(\dot{y}^{2}+y^{2}\right) d t\right. \\
\left.=\int_{0}^{\infty} y^{2} F\left(y^{2}, \tau\right) d \tau\right\} .
\end{gathered}
$$

Note that admissible functions are differentiable at $t=0$, and that $J(y)$ might be an improper integral at $t=0$ since $G$ might be singular there.

Lemma 1. If $y$ satisfies $y \in D^{\prime}[0, \infty), y(0)=0, y(t) \not \equiv 0, y(t) \geqq 0$, and if

$$
\sigma^{2} \equiv \int_{0}^{\infty}\left(\dot{y}^{2}+y^{2}\right) d t \quad \text { exists }
$$

then $\int_{0}^{\infty} y^{2} F\left(y^{2}, t\right) d t$ and $\int_{0}^{\infty} G\left(y^{2}, t\right) d t$ both exist, and $\exists \alpha>0$ such that $\alpha y \in A$.

Proof. Appendix.

Thus the last condition in the definition of $A$ may be viewed as a normalization.

Lemma 2. $\operatorname{Inf}_{A} J(y)=\lambda \geqq 0$. There exists a minimizing sequence $\left\{y_{n}\right\} \subset A$ that converges on $[0, \infty)$, uniformly on compact subintervals, to $y(t) \in C[0, \infty)$, and $J\left(y_{n}\right) \geqq \delta(\delta+1)^{-1} \sigma_{n}^{2}$, where $\delta$ is defined in II.

Proof. Appendix. We do not claim $y \in A$ or even $y \in D^{\prime}[0, \infty)$, 
thus $J(y)$ may not exist. Throughout the remainder of this paper, $\left\{y_{n}\right\}$ will be a minimizing sequence.

LEMmA 3. For each $y_{n}(t)$, and any constant $\alpha_{n}>0$, the function

$$
u_{n}(t)=\alpha_{n} e^{-t} \int_{0}^{t}(\sinh \tau) y_{n} F\left(y_{n}^{2} \tau\right), d \tau+\alpha_{n} \sinh t \int_{t}^{\infty} e^{-\tau} y_{n} F\left(y_{n}^{2}, \tau\right) d \tau
$$

is in $C^{1}[0, \infty) \cap C^{2}(0, \infty)$ and solves

$$
\ddot{u}_{n}-u_{n}+\alpha_{n} y_{n} F\left(y_{n}^{2}, t\right)=0, t \in(0, \infty), u_{n}(0)=0=\lim _{t \rightarrow \infty} u_{n}(t) .
$$

Also, (8) $\lim _{t \rightarrow 0} \dot{u}_{n}(t)$ exists, $\lim _{t \rightarrow \infty} \dot{u}_{n}(t)=0$. We can choose $\alpha_{n}$ so that $u_{n} \in A$, and we will then have $\left\{\alpha_{n}\right\}$ bounded, and $J\left(u_{n}\right) \leqq J\left(y_{n}\right)$ for all $n$. Furthermore, $J\left(u_{n}\right)=J\left(y_{n}\right)$ if and only if $u_{n} \equiv y_{n}$. Finally, $\exists u_{0} \in C[0, \infty)$ such that $\lim _{n \rightarrow \infty} u_{n}(t)=u_{0}(t)$ for $t \in[0, \infty)$, uniformly on compact subsets.

Proof. Appendix. Note that the BVP for $u_{n}(t)$ may be singular at $t=0$. Since $\left\{\alpha_{n}\right\}$ is bounded, we shall assume henceforth, by using a subsequence if necessary, that $\lim _{n \rightarrow \infty} \alpha_{n}=\alpha_{0}$.

Lemma 3 implies that $\left\{u_{n}\right\}$ is a minimizing sequence of admissible functions. Thus we can repeat the procedure described in Lemma 3 , starting with $\left\{u_{n}\right\}$ as our new minimizing sequence. We can do this any finite number of times. We will still call the solution $u_{n}$, and the last-used minimizing sequence $\left\{y_{n}\right\}$.

LemMa 4. We can iterate the procedure of Lemma 3 a finite number of times, to obtain $y_{n}(t)=0(t)$, uniformly in $n$, as $t \rightarrow 0$.

Proof. Appendix. If is interesting that Sansone also uses an iterative procedure in a completely different context to get the full parameter range $1<k<5$. (Cf. [4], pp. 22-29.)

By Lemma 4, we may assume throughout the remainder of this paper that $y_{n}(t)=0(t)$ as $t \rightarrow 0$, uniformly in $n$.

Lemma 5. $\left\{\dot{u}_{n}(t)\right\}$ is a Cauchy sequence, uniformly on $[0, \infty)$, hence $\lim _{n \rightarrow \infty} \dot{u}_{n}(t)=\dot{u}_{0}(t)$ exists on $[0, \infty)$.

Proof. Appendix.

LEMMA 6. $u_{0} \in A, \quad \lim _{n \rightarrow \infty} J\left(u_{n}\right)=J\left(u_{0}\right)$, and $\lambda \equiv \inf _{A} J(y)=$ $\lim _{n \rightarrow \infty} J\left(u_{n}\right)=J\left(u_{0}\right)>0$, hence $u_{0}$ is minimizing and nontrivial.

Proof. Appendix. 
LEMMA 7. $\lim _{n \rightarrow \infty} \alpha_{n} \equiv \alpha_{0}=1$, and $u_{0}(t)$ solves the $B V P(1)$ (2).

ACKNowledgments. Research for this paper was supported, in part, by the National Research Council of Canada under grants NRC-A-1476 and NRC-T1093. The paper was written while the author was on sabbatical leave at the University of Minnesota, and the author is grateful for the financial support of the University of Alberta and the facilities provided by the University of Minnesota.

APPendix. Proofs. Throughout this section, $K, L, M$ will denote various unimportant constants needed in the course of arguments.

Proof of Lemma 1. For $0 \leqq y \in D^{\prime}[0, \infty)$ with $y(0)=0$, we have, for $t$ small

$$
y(t)=\dot{y}(0)[t+o(t)] \leqq K t, \quad K=K(y) ;
$$

while standard inequalities imply

$$
\begin{gathered}
y^{2}(t)=\left(\int_{0}^{t} \dot{y}(\tau) d \tau\right)^{2} \leqq t \int_{0}^{t} \dot{y}^{2}(\tau) d \tau \leqq t \int_{0}^{t}\left(\dot{y}^{2}+y^{2}\right) d \tau \equiv t \sigma^{2}(t) \leqq t \sigma^{2}, \\
y^{2}(t)=2 \int_{0}^{t} y(\tau) \dot{y}(\tau) d \tau \leqq \int_{0}^{t}\left(y^{2}+\dot{y}^{2}\right) d \tau \equiv \sigma^{2}(t) \leqq \sigma^{2} ;
\end{gathered}
$$

(11) is useful for $t$ small, (12) for $t$ large. Now if $\sigma^{2}$ exists for a given $y$, then $\int_{a}^{T} y^{2} F\left(y^{2}, \tau\right) d \tau=\left(\int_{a}^{1}+\int_{1}^{T}\right)\left[y^{2} F\left(y^{2}, \tau\right)\right] d \tau$, so we can use (11) in the first integral, and (12) in the second, to obtain

$$
\int_{a}^{T} y^{2} F\left(y^{2}, \tau\right) d \tau \leqq \int_{a}^{1} \sigma^{2} \tau F\left(\sigma^{2} \tau, \tau\right) d \tau+\int_{1}^{T} y^{2} F\left(\sigma^{2}, \tau\right) d \tau
$$

The first integral on the right converges as $a \rightarrow 0$, by IV, and the second is bounded above by $\sigma^{2} \max _{[1, \infty)} F\left(\sigma^{2}, t\right)$. For $\int_{0}^{\infty} G\left(y^{2}, \tau\right) d \tau$, we note that (13) $G\left(y^{2}, \tau\right)=\int_{0}^{y^{2}} F(\eta, \tau) d \eta \leqq y^{2} F\left(y^{2}, \tau\right)$. We now define $H(\alpha)=\left[\int_{0}^{\infty} y^{2} F\left(\alpha^{2} y^{2}, \tau\right) d \tau\right] / \sigma^{2}$. (This integral is easily shown to converge.) By II,

$$
\begin{aligned}
& 0<\alpha<1 \Rightarrow H(\alpha) \leqq \alpha^{2 \delta} H(1), \\
& 1 \leqq \alpha \Longrightarrow \alpha^{2 \delta} H(1) \leqq H(\alpha),
\end{aligned}
$$

which implies that $H(\alpha)$ maps $(0, \infty)$ onto $(0, \infty)$. Thus $H(\alpha)=1$ for exactly one $\alpha>0$ ( $H$ is strictly increasing). Then $\alpha y$ will satisfy the normalization condition. 
Proof of Lemma 2. If $y$ is admissible, $\sigma^{2}$ exists by the normalization condition in the definition of $A$, thus $\int_{0}^{\infty} G\left(y^{2}, \tau\right) d \tau$ exists by Lemma 1, and $J(y)$ may be computed. By (12),

$$
J(y)=\sigma^{2}-\int_{0}^{\infty} G\left(y^{2}, \tau\right) d \tau \geqq \sigma^{2}-\int_{0}^{\infty} y^{2} F\left(y^{2}, \tau\right)=0 .
$$

Clearly there exists a minimizing sequence of nontrivial functions $\left\{y_{n}\right\} \subset A$ such that $J\left(y_{n}\right) \rightarrow \lambda \equiv \inf _{A} J(y) \geqq 0$. Therefore, there exists a number $\rho^{2}>0$ such that $J\left(y_{n}\right) \leqq \rho^{2}$ for all $n$.

Now by II and the normalization condition for $A$, if $y \in A$,

$$
\begin{aligned}
\int_{0}^{\infty} G\left(y^{2}, \tau\right) d \tau & =\int_{0}^{\infty}\left[\int_{0}^{y^{2}} \eta^{\delta} \eta^{-\delta} F(\eta, \tau) d \eta\right] d \tau \leqq \int_{0}^{\infty} y^{-2 \delta} F\left(y^{2}, \tau\right)\left[\int_{0}^{y^{2}} \eta^{\delta} d \eta\right] d \tau \\
& \leqq(\delta+1)^{-1} \int_{0}^{\infty} y^{2} F\left(y^{2}, \tau\right) d \tau=(\delta+1)^{-1} \sigma^{2}
\end{aligned}
$$

thus $J(y)=\sigma^{2}-\int_{0}^{\infty} G\left(y^{2}, \tau\right) d \tau \geqq \delta(\delta+1)^{-1} \sigma^{2}$. For the minimizing sequence $\left\{y_{n}\right\}$, we conclude that

$$
\rho^{2} \geqq J\left(y_{n}\right) \geqq \delta(\delta+1)^{-1} \sigma_{n}^{2}>\delta(\delta+1)^{-1} \int_{0}^{\infty} \dot{y}_{n}^{2} d \tau
$$

Since $y_{n}(0)=0$, the Ascoli-Arzela theorem applies, and by using a subsequence if necessary we can assume $\lim _{n \rightarrow \infty} y_{n}(t)=y(t)$ exists, the convergence is uniform on compact subintervals, and $y \in C[0, \infty)$.

Now $J\left(y_{n}\right) \leqq \rho^{2}$ for all $n$ implies $\sigma^{2} \leqq((\delta+1) / \delta) \rho^{2}$, so by relabelling the constant we can write, by (11), (12),

(a) $y_{n}^{2}(t) \leqq \rho^{2} t$

(b) $y_{n}^{2}(t) \leqq \rho^{2} \quad$ uniformly in $n$.

Proof of Lemma 3. Following Ryder, we rewrite (6) as $u_{n}(t)=$ $\alpha_{n} e^{-t} Q(t)+\alpha_{n}(\sinh t) R(t)$. We can use (14a), IV, and the fact that $\sinh t=0(t)$ for $t$ small to conclude that

$$
Q(t) \equiv \int_{0}^{t}(\sinh \tau) y_{n} F\left(y_{n}^{2}, \tau\right) d \tau \leqq K t^{1 / 2+\varepsilon} \int_{0}^{t} \tau^{1-\varepsilon} F\left(\rho^{2} \tau, \tau\right) d \tau=o\left(t^{1 / 2+\varepsilon}\right)
$$

as $t \rightarrow 0$, uniformly in $n$. If we use (10) instead of !(14a), and II, we get

$$
Q(t) \leqq L_{n} t^{1+\varepsilon} \int_{0}^{t} \tau^{1-\varepsilon} F\left(K_{n}^{2} \tau^{2}, \tau\right) d \tau \leqq M_{n} t^{1+\varepsilon+\delta} \int_{0}^{t} \tau^{1-\varepsilon} F(\tau, \tau) d \tau .
$$

Thus $Q(t)=O_{n}\left(t^{1+\varepsilon+\delta}\right)$, which is considerably stronger (for a given $n$ ) then the uniform bound (15). To estimate $R(t)$ for $t$ small, we use (14), I, III, and IV to obtain 


$$
\begin{aligned}
& (\sinh t) R(t) \equiv \sinh t\left(\int_{t}^{1}+\int_{1}^{\infty}\right)\left(e^{-\tau} y_{n} F\left(y_{n}^{2}, \tau\right) d \tau\right) \\
& \leqq(\sinh t) t^{\varepsilon-1 / 2} \int_{t}^{1} \tau^{1 / 2-\varepsilon} \rho \tau^{1 / 2} F\left(\rho^{2} \tau, \tau\right) d \tau+\sinh t \int_{1}^{\infty} e^{-\tau} \rho^{2} F\left(\rho^{2}, \tau\right) d \tau \\
& \leqq K t^{1 / 2+\varepsilon} \int_{t}^{1} \tau^{1-\varepsilon} F\left(\rho^{2} \tau, \tau\right) d \tau+L t \max _{[1, \infty)} F\left(\rho^{2}, \tau\right) \int_{1}^{\infty} e^{-\tau} d \tau \\
& \quad=O\left(t^{1 / 2+\varepsilon}\right)+O(t),
\end{aligned}
$$

as $t \rightarrow 0$, uniformly in $n$. If we use the nonuniform bound (10) we get $\sinh t R(t)=O_{n}(t)$.

Applying II and (14b), we get for $t$ large and $0<T<t$,

$$
e^{-t} Q(t) \leqq K e^{-t} \int_{0}^{T} \tau \rho \tau^{1 / 2} F\left(\rho^{2} \tau, \tau\right) d \tau+L e^{-t} \int_{T}^{t} e^{\tau} \rho F\left(\rho^{2}, \tau\right) d \tau
$$

If we choose $T$ so that $F\left(\rho^{2}, \tau\right)<\varepsilon$ for $\tau>T$, the above inequality implies $\lim \sup _{t \rightarrow \infty} e^{-t} Q(t) \leqq L \rho \varepsilon$, thus $\lim _{t \rightarrow \infty} e^{-t} Q(t)=0$. For $R(t)$ we get

(19) $\quad(\sinh t) R(t) \leqq e^{t} \int_{t}^{\infty} e^{-\tau} \rho^{2} F\left(\rho^{2}, \tau\right) d \tau \leqq \rho^{2} \max _{[t, \infty)} F\left(\rho^{2}, \tau\right)=o(1)$ as $t \rightarrow \infty$.

It is easy to see that $\dot{u}_{n}(t)=-e^{-t} Q(t)+(\cosh t) R(t)$, and that $u_{n}(t)$ solves the differential equation in $(7)$ on $(0, \infty)$. The boundary conditions are easily verified, using the estimates above. Using the (nonuniform) estimates $\sinh t R(t)=O_{n}(t)$ as $t \rightarrow 0$, we see that $R(t)=O_{n}(1)$, and we can conclude that $\dot{u}_{n}(0)$ exists, since the integral defining $R(0)$ must either diverge to $+\infty$ or exist as a real number. Also, $\lim _{t \rightarrow \infty} \dot{u}_{n}(t)=0$ follows easily from the above estimates. If we alternately multiply $(7)$ by $u_{n}(t), y_{n}(t)$, and integrate by parts, we obtain respectively

$$
\begin{gathered}
s_{n}^{2}(T) \equiv \int_{0}^{T_{i}}\left(\dot{u}_{n}^{2}+u_{n}^{2}\right) d \tau=\alpha_{n} \int_{0}^{T} u_{n} y_{n} F\left(y_{n}^{2}, \tau\right) d \tau+u_{n}(T) \dot{u}_{n}(T) \\
\int_{0}^{\infty}\left(\dot{y}_{n} \dot{u}_{n}+y_{n} u_{n}\right) d \tau=\alpha_{n} \int_{0}^{\infty} y_{n}^{2} F\left(y_{n}^{2}, \tau\right) d \tau=\alpha_{n} \int_{0}^{\infty}\left(\dot{y}_{n}^{2}+y_{n}^{2}\right) d \tau=\alpha_{n} \sigma_{n}^{2} .
\end{gathered}
$$

Now by (11) and (14a),

$$
\begin{aligned}
& \int_{0}^{1} u_{n} y_{n} F\left(y_{n}^{2}, \tau\right) d \tau \leqq s_{n}(T) \rho \int_{0}^{1} \tau F\left(y_{n}^{2}, \tau\right) d \tau, \text { and similarly } \\
& \int_{1}^{T} u_{n} y_{n} F\left(y_{n}^{2}, \tau\right) d \tau \leqq \max _{[1, \infty)} F\left(\rho^{2}, \tau\right) \int_{1}^{T} u_{n} y_{n} \leqq K\left(\int_{1}^{T} u_{n}^{2}\right)^{1 / 2}\left(\int_{1}^{T} y_{n}^{2}\right)^{1 / 2} \\
& \leqq K \rho s_{n}(T)
\end{aligned}
$$

Then (20) implies $s_{n}^{2}(T) \leqq L_{n} s_{n}(T)+u_{n}(T) \dot{u}_{n}(T)$, so $\left(s_{n}^{2}(T)-L_{n} / 2\right)^{2} \leqq$ $\left(L_{n}^{2} / 4\right)+u_{n}(T) \dot{u}_{n}(T)$. Therefore $\int_{0}^{\infty}\left(\dot{u}_{n}^{2}+u_{n}^{2}\right) d \tau \equiv s_{n}^{2}$ exists. We then 
conclude from Lemma 1 that $\alpha u_{n}$ is admissible for some $\alpha>0$. This just corresponds to an appropriate choice of $\alpha_{n}$ in the integral (6) that defines $u_{n}$, and we so choose $\alpha_{n}$. In exactly the same way as for $\left\{y_{n}\right\}$, we can then show $\lim _{n \rightarrow \infty} u_{n}(t)=u_{0}(t)$ exists.

Using (21) and the Cauchy-Schwarz inequality, we obtain

$$
\begin{gathered}
{\left[\alpha_{n} \int_{0}^{\infty} y_{n}^{2} F\left(y_{n}^{2}, \tau\right) d \tau\right]^{2}<\int_{0}^{\infty}\left(\dot{u}_{n}^{2}+u_{n}^{2}\right) d \tau \int_{0}^{\infty}\left(\dot{y}_{n}^{2}+y_{n}^{2}\right) d \tau} \\
=\int_{0}^{\infty} u_{n}^{2} F\left(u_{n}^{2}, \tau\right) d \tau \int_{0}^{\infty} y_{n}^{2} F\left(y_{n}^{2}, \tau\right) d \tau,
\end{gathered}
$$

which implies $\alpha_{n}^{2} \int_{0}^{\infty} y_{n}^{2} F\left(y_{n}^{2}, \tau\right) d \tau \leqq \int_{0}^{\infty} u_{n}^{2} F\left(u_{n}^{2}, \tau\right) d \tau$. Now by $(20)$ and the normalization condition,

$$
\begin{gathered}
{\left[\int_{0}^{\infty} u_{n}^{2} F\left(u_{n}^{2}, \tau\right) d \tau\right]^{2}=\left[\int_{0}^{\infty}\left(\dot{u}_{n}^{2}+u_{n}^{2}\right) d \tau\right]^{2}=\alpha_{n}^{2}\left[\int_{0}^{\infty} u_{n} y_{n} F\left(y_{n}^{2}, \tau\right) d \tau\right]^{2}} \\
\leqq \alpha_{n}^{2} \int_{0}^{\infty} u_{n}^{2} F\left(y_{n}^{2}, \tau\right) d \tau \int_{0}^{\infty} y_{n}^{2} F\left(y_{n}^{2}, \tau\right) d \tau
\end{gathered}
$$

combining the two above results, we get

$$
\int_{0}^{\infty} u_{n}^{2} F\left(u_{n}^{2}, \tau\right) d \tau \leqq \int_{0}^{\infty} u_{n}^{2} F\left(y_{n}^{2}, \tau\right) d \tau \text {. }
$$

Since $F(\eta, t)$ is strictly increasing in $\eta$, the function $G(\eta, t)=$ $\int_{0}^{\eta} F(\gamma, t) d \gamma$ is strictly convex and

$$
\int_{0}^{T} G\left(u_{n}^{2}, \tau\right) d \tau \geqq \int_{0}^{T} G\left(y_{n}^{2}, \tau\right) d \tau+\int_{0}^{T}\left(u_{n}^{2}-y_{n}^{2}\right) F\left(y_{n}^{2}, \tau\right) d \tau,
$$

where equality holds if and only if $u_{n}^{2}(\tau) \equiv y_{n}^{2}(\tau)$ on $[0, T]$. Therefore, using (23), we obtain

$$
\int_{0}^{\infty}\left[u_{n}^{2} F\left(u_{n}^{2}, \tau\right)-G\left(u_{n}^{2}, \tau\right)\right] d \tau \leqq \int_{0}^{\infty}\left[y_{n}^{2} F\left(y_{n}^{2}, \tau\right)-G\left(y_{n}^{2}, \tau\right)\right] d \tau .
$$

But $J(w)=\int_{0}^{\infty}\left[w^{2} F\left(w^{2}, \tau\right)-G\left(w^{2}, \tau\right)\right] d \tau$ for $w \in A$, hence, the above inequality implies $J\left(u_{n}\right) \leqq J\left(y_{n}\right)$. If $J\left(u_{n}\right)=J\left(y_{n}\right)$, then (24) reduces to an equality, and $u_{n}(t) \equiv y_{n}(t)$ on $[0, \infty)$.

Finally, we shall show that $\left\{\alpha_{n}\right\}$ is bounded. We have by (22)

$$
\alpha_{n}^{2} \leqq\left[\int_{0}^{\infty} y_{n}^{2} F\left(y_{n}^{2}, \tau\right) d \tau\right]^{-1} \int_{0}^{\infty} u_{n}^{2} F\left(u_{n}^{2}, \tau\right) d \tau \text {. }
$$

Using (14) (since $\left\{u_{n}\right\}$ is minimizing), I and III, we obtain

$$
\int_{0}^{\infty} u_{n}^{2} F\left(u_{n}^{2}, \tau\right) d \tau \leqq \rho^{2} \int_{0}^{1} \tau F\left(\rho^{2} \tau, \tau\right) d \tau+\rho^{2} \max _{[1, \infty)} F\left(\rho^{2}, \tau\right),
$$


so the numerator in (25) is bounded above. To bound the denominator below, we use the normalization condition (11), and (12), to obtain

$$
\begin{aligned}
\sigma_{n}^{2}= & \int_{0}^{\infty}\left(\dot{y}_{n}^{2}+y_{n}^{2}\right) d \tau=\int_{0}^{\infty} y_{n}^{2} F\left(y_{n}^{2}, \tau\right) d \tau \leqq \int_{0}^{1} \sigma_{n}^{2} \tau F\left(\sigma_{n}^{2} \tau, \tau\right) d \tau \\
& +\sigma_{n}^{2} \max _{[1, \infty)} F\left(\sigma_{n}^{2}, \tau\right)
\end{aligned}
$$

thus

$$
1 \leqq \int_{0}^{1} \tau F\left(\sigma_{n}^{2} \tau, \tau\right) d \tau+\max _{[1, \infty)} F\left(\sigma_{n}^{2}, \tau\right) \leqq K \sigma_{n}^{2 \delta} .
$$

Therefore $\sigma_{n}^{2} \geqq M>0$ for all $n$, and this implies that the denominator in (25) is bounded below, since $\int_{0}^{\infty} y_{n}^{2} F\left(y_{n}^{2}, \tau\right) d \tau=\sigma_{n}^{2}$.

Proof of Lemma 4. Without loss of generality, we shall assume that $\lim \alpha_{n}=\alpha_{0}$ exists for any specific given minimizing sequence $\left\{y_{n}\right\}$ and corresponding solutions of $(7),\left\{u_{n}\right\}$. Since the members of the first minimizing sequence satisfy $y_{n}(t) \leqq \rho t^{1 / 2}$ on $[0,1]$ and $\left\{\alpha_{n}\right\}$ is bounded, (15) and (17) imply $u_{n}(t)=O\left(t^{1 / 2+\varepsilon}\right)$ as $t \rightarrow 0$, uniformly in $n$. Now suppose we have iterated $p \geqq 0$ times and obtained $u_{n}(t)=O\left(t^{1 / 2+\mu}\right)$ with $1 / 2+\mu<1$. We then parallel the derivation of (15), (17) to write

$$
\begin{aligned}
Q(t) & \leqq K \int_{0}^{t} \tau \tau^{1 / 2+\mu} F\left(L^{\prime} \tau^{1+2 \mu}, \tau\right) d \tau \leqq K_{2} \int_{0}^{t} \tau^{\mu(2 \tilde{o}+1)+3 / 2} F(\tau, \tau) d \tau \\
& =O\left(t^{1 / 2+\nu}\right)
\end{aligned}
$$

where

$$
\nu=\mu(1+2 \delta) .
$$

Clearly we can make $\nu>1$ after a finite number of such iterations, beginning with $\mu=\varepsilon$.

Proof of Lemma 5. We may assume, using Lemma 4, that $y_{n}(t)=O(t)$ as $t \rightarrow 0$, uniformly in $n$. Now $\dot{u}_{n}(t)=-e^{-t} Q_{n}(t)+$ $(\cosh t) R_{n}(t)$; where we have introduced subscripts to indicate dependence on $y_{n}$. It is now easy to show that $\left\{Q_{n}\right\},\left\{R_{n}\right\}$ converge uniformly on $[0, \infty)$, hence so does $\left\{\dot{u}_{n}(t)\right\}$; for example,

$$
\begin{aligned}
& \left|R_{n}(t)-R_{m}(t)\right| \leqq\left(\int_{t}^{1}+\int_{1}^{\infty}\right) e^{-\tau}\left|y_{n} F\left(y_{n}^{2}, \tau\right)-y_{m} F\left(y_{m}^{2}, \tau\right)\right| d \tau \\
& \quad \leqq \int_{0}^{t_{0}} e^{-\tau} M \tau F\left(M^{2} \tau^{2}, \tau\right)+\int_{t_{0}}^{T} e^{-\tau} O(1) d \tau+\int_{T}^{\infty} e^{-\tau} 2 \rho F\left(\rho^{2}, \tau\right) d \tau,
\end{aligned}
$$


where we have used Lemma $4\left(y_{n}(\tau) \leqq M \tau\right)$ in the first integral, and the $O(1)$ in the middle integral is as $n, m \rightarrow \infty$, uniformly on a fixed interval $\left[t_{0}, T\right]$ (since $\left\{y_{n}\right\}$ is uniformly Cauchy there). We choose $t_{0}$ so small that the first integral is less than $\varepsilon / 3, T$ so large that the last is less than $\varepsilon / 3$ (both are uniform in $m, n$ ), then let $m, n \rightarrow \infty$ in the middle.

Proof of Lemma 6. By standard arguments, Lemma 5 implies

$$
\lim _{n \rightarrow \infty} u_{n}(t)=u_{0}(t), \quad \lim _{n \rightarrow \infty} \dot{u}_{n}(t)=\dot{u}_{0}(t),
$$

uniformly on compact subsets. However, uniform estimates like those in (27) enable us to conclude $\lim J\left(u_{n}\right)=J\left(u_{0}\right)$ (see Ryder, pp. 489-490 for details). By the remarks following (26), we have $\int_{0}^{\infty} \dot{y}_{n}^{2}+y_{n}^{2}=\int_{0}^{\infty} y_{n}^{2} F\left(y_{n}^{2}, \tau\right) d \tau \geqq A^{2}>0$, and by Lemma $2, J\left(y_{n}\right) \geqq$ $A^{2}>0$.

Proof of Lemma 7. We pick $u_{0}(t)$ for the function $y(t)$ appearing in the BVP (7). Then $u(t)$ as defined by (6) must satisfy $J(u) \leqq$ $J\left(u_{0}\right)$ which implies $J(u)=J\left(u_{0}\right)$, thus $u(t) \equiv u_{0}(t)$. Therefore $u_{0}(t)$ solves (7) with $y(t)=u_{0}(t)$, and some $\alpha_{0}>0$. In particular $\lim _{t \rightarrow 0} u_{0}(t)=$ $\lim _{t \rightarrow \infty} u_{0}(t)=0$. By (20) (letting $T \rightarrow \infty$ ),

$$
\sigma_{0}^{2} \equiv \int_{0}^{\infty}\left(\dot{u}_{0}^{2}+u_{0}^{2}\right) d \tau=\alpha_{0} \int_{0}^{\infty} u_{0}^{2} F\left(u_{0}^{2}, \tau\right) d \tau,
$$

then by the normalizing condition for $A, \alpha_{0}=1$. Thus $u_{0}(t)$ solves (1) (2).

\section{REFERENCES}

1. Z. Nehari, On a nonlinear differential equation arising in nuclear physics, Proc. Royal Irish Acad., 62 (1963), 117-135.

2. - Characteristic values associated with a class of non linear second-order differential equations, Acta Math., 105 (1961), 141-175.

3. G. Ryder, Boundary value problems for a class of nonlinear differential equations, Pacific J. Math., 22 (1967), 477-503.

4. G. Sansone, Su un'equazione differenziale non lineare della fisica nucleare, Symposia Math., Vol. VI (1971), 3-139.

5. J. L. Synge, On a certain nonlinear differential equation, Proc. Royal Irish Acad., 62 (1961), 19-41.

6. K. Takahashi, The structure of the nucleon core by the Hartree approximation, Nuclear Physics, 26 (1961), 658-669.

Received October 8, 1977.

UNIVERSITy OF ALBERTA

Edmonton, Alberta, Canada 



\title{
PACIFIC JOURNAL OF MATHEMATICS
}

\section{EDITORS}

RICHARD ARENS (Managing Editor)

University of California

Los Angeles, CA 90024

Charles W. Curtis

University of Oregon

Eugene, OR 97403

C. C. MOORE

University of California

Berkeley, CA 94720

\section{J. DUGUNDJI}

Department of Mathematics University of Southern California Los Angeles, CA 90007

R. Finn and J. Milgram

Stanford University

Stanford, CA 94305

\section{ASSOCIATE EDITORS}
E. F. BECKENBACH
B. H. NeumanN
F. WOLF
K. YOSHIDA

\section{SUPPORTING INSTITUTIONS}

\author{
UNIVERSITY OF BRITISH COLUMBIA \\ CALIFORNIA INSTITUTE OF TECHNOLOGY \\ UNIVERSITY OF CALIFORNIA \\ MONTANA STATE UNIVERSITY \\ UNIVERSITY OF NEVADA, RENO \\ NEW MEXICO STATE UNIVERSITY \\ OREGON STATE UNIVERSITY \\ UNIVERSITY OF OREGON
}

\author{
UNIVERSITY OF SOUTHERN CALIFORNIA \\ STANFORD UNIVERSITY \\ UNIVERSITY OF HAWAII \\ UNIVERSITY OF TOKYO \\ UNIVERSITY OF UTAH \\ WASHINGTON STATE UNIVERSITY \\ UNIVERSITY OF WASHINGTON
}

The Supporting Institutions listed above contribute to the cost of publication of this Journal, but they are not owners or publishers and have no responsibility for its content or policies.

Mathematical papers intended for publication in the Pacific Journal of Mathematics should be in typed form or offset-reproduced, (not dittoed), double spaced with large margins. Please do not use built up fractions in the text of the manuscript. However, you may use them in the displayed equations. Underline Greek letters in red, German in green, and script in blue. The first paragraph or two must be capable of being used separately as a synopsis of the entire paper. Items of the bibliography should not be cited there unless absolutely necessary, in which case they must be identified by author and journal, rather than by item number. Manuscripts, in triplicate, may be sent to any one of the editors. Please classify according to the scheme of Math. Reviews, Index to Vol. 39. All other communications should be addressed to the managing editor, or Elaine Barth, University of California, Los Angeles, California, 90024.

50 reprints to each author are provided free for each article, only if page charges have been substantially paid. Additional copies may be obtained at cost in multiples of 50 .

The Pacific Journal of Mathematics is issued monthly as of January 1966. Regular subscription rate: $\$ 72.00$ a year (6 Vols., 12 issues). Special rate: $\$ 36.00$ a year to individual members of supporting institutions.

Subscriptions, orders for numbers issued in the last three calendar years, and changes of address should be sent to Pacific Journal of Mathematics, P.O. Box 969, Carmel Valley, CA 93924, U.S.A. Older back numbers obtainable from Kraus Periodicals Co., Route 100, Millwood, NY 10546.

PUBLISHED BY PACIFIC JOURNAL OF MATHEMATICS, A NON-PROFIT CORPORATION

Printed at Kokusai Bunken Insatsusha (International Academic Printing Co., Ltd.). 8-8, 3-chome, Takadanobaba, Shinjuku-ku, Tokyo 160, Japan.

Copyright (C) 1978 by Pacific Journal of Mathematics Manufactured and first issued in Japan 


\section{Pacific Journal of Mathematics \\ Vol. 78, No. $2 \quad$ April, 1978}

Su-Shing Chen, Weak rigidity of compact negatively curved manifolds .... 273

Heinz Otto Cordes and D. A. Williams, An algebra of pseudodifferential operators with nonsmooth symbol ....................... 279

Herbert Paul Halpern, Normal expectations and integral decomposition of type III von Neumann algebras ......................... 291

G. Hochschild, On representing analytic groups with their

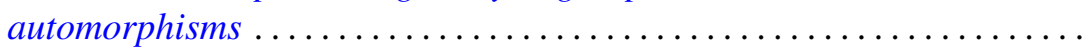

Dean G. Hoffman and David Anthony Klarner, Sets of integers closed under affine operators - the closure of finite sets ....................

Simeon Ivanov, On holomorphic relative inverses of operator-valued

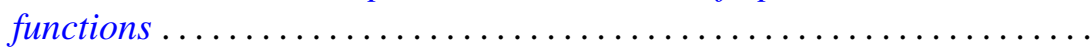

O. P. Juneja and M. L. Mogra, Radii of convexity for certain classes of

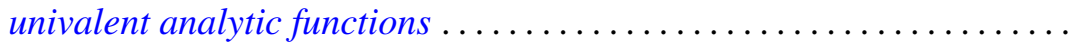

Hadi Kharaghani, The evolution of bounded linear functionals with application to invariant means.......................... 369

Jack W. Macki, A singular nonlinear boundary value problem .......... 375

A. W. Mason and Walter Wilson Stothers, Remarks on a theorem of $L$. Greenberg on the modular group ........................ 385

Kevin Mor McCrimmon, Peirce ideals in Jordan algebras . . . . . . . . . . . 397

John C. Morgan, II, On the absolute Baire property ................ 415

Gerard J. Murphy, Commutative non-Archimedean $C^{*}$-algebras ...

Masafumi Okumura, Submanifolds with L-flat normal connection of the

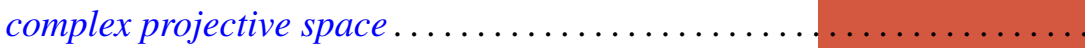

Chull Park and David Lee Skoug, Distribution estimates of barrier-crossing probabilities of the Yeh-Wiener process ...............

Irving Reiner, Invariants of integral representations ........

Phillip Schultz, The typeset and cotypeset of a rank 2 abelian group ..... 503

John Brendan Sullivan, Representations of Witt groups ....

Chia-Chi Tung, Equidistribution theory in higher dimensions . . . 